\title{
Perencanaan Strategis TI dalam Pengembangan SI Pelayanan Publik (Studi Kasus: Kejati Sumsel)
}

\author{
Khairunnisah $^{1}$, Edi Surya Negara ${ }^{* 2}$, Dedy Syamsuar ${ }^{3}$, Yesi Novaria Kunang ${ }^{4}$ \\ Magister Teknik Informatika, Universitas Bina Darma, Palembang, Sumatera Selatan \\ e-mail: ${ }^{1}$ nisakhai05@gmail.com, ${ }^{2}$ e.s.negara@binadarma.ac.id , \\ 3 dedy_syamsuar@binadarma.ac.id ${ }^{4}$ yesinovariakunang@binadarma.ac.id
}

\begin{abstract}
Abstrak: Kehadiran era revolusi industri 4.0 mengharuskan setiap instansi pemerintahan dapat memanfaatkan teknologi informasi dan komunikasi sepenuhnya terutama dalam hal melayani masyarakat. Oleh karena itu Kejaksaan Tinggi Sumatera Selatan dituntut untuk terus mengembangkan sistem informasi guna mempercepat pelayanan dan penyebaran informasi yang lebih efektif dan efisien. Dalam hal ini sebelum melakukan pengembangan sistem, penulis akan menganalisis rencana strategis yang tepat dengan menggunakan metodologi Joe Ward and Peppard yaitu salah satunya dengan metode SWOT, Critical Success Factor (CSF), dan Value Chain. Dari hasil ketiga analisis tersebut didapatkan strategi tumbuh yang tergambar melalui diagram kuadran yang artinya disetujui untuk dikembangkannya sistem informasi dengan menggunakan Standar Revolusi Industri 4.0 agar terwujudnya pelayanan masyarakat melalui satu pintu secara terpadu.
\end{abstract}

Kata kunci-Rencana Strategis, Metodologi Joe Ward and Peppard, Analisis SWOT, Critical Success Factor (CSF), dan Value Chain.

Abstract: The presence of the 4.0 industrial revolution era requires that every government offices take full advantages of information and communication technology, especially in terms of providing services to public. Therefore, Kejaksaan Tinggi Sumatera Selatan is required to continue to develop information systems in order to accelerate services and to disseminate information more effective and efficient. In this case, before developing the system, the author will analyze the right strategic plan using the Joe Ward and Peppard methodology, one of which is the SWOT method, Critical Success Factor (CSF), and Value Chain. From the results of the three analyzes, a growth strategy is obtained which is illustrated by a quadrant diagram, it means that it is approved to develop an information system using the Industrial Revolution Standard 4.0. to create integrated services to the public through one door in an integrated manner.

Keywords - Strategic Plan, Joe Ward and Peppard Methodology, SWOT Analysis, Critical Success Factor (CSF), and Value Chain.

\section{PENDAHULUAN}

$\mathrm{P}$ erkembangan teknologi dan sistem informasi di Indonesia saaat ini tidak hanya dimanfaatkan oleh dunia industri tetapi juga dimanfaatkan oleh pemerintah dalam melakukan perannya menjalankan pemerintahan khususnya untuk pelayanan publik. Pelayanan menjadi tugas utama dari sosok aparatur sebagai abdi negara dan abdi masyarakat khususnya pada Kejaksaan Tinggi Sumatera Selatan. Tugas ini telah jelas digariskan dalam pembukaan UUD 1945 yang diperjelas lagi dalam Keputusan Menteri Pendayagunaan Aparatur 
Negara No.63 tahun 2003 yang menguraikan pedoman umum penyelenggaraan pelayanan sistem [1].

Pelayanan sistem yang berkualitas atau yang biasa disebut dengan pelayanan prima merupakan pelayanan terbaik yang memenuhi standar kualitas pelayanan. Pada saat ini telah lahir istilah Industri 4.0 yang keberadaannya menawarkan banyak potensi. Industri 4.0 melalui konektivitas dan digitalisasinya mampu meningkatkan efisiensi rantai manufaktur dan kualitas produk.

Untuk mencapai standar Industri 4.0 dibutuhkan suatu perencanaan strategis yang terukur dan akurat. Salah satu metodologi yang dapat digunakan untuk merancang perencanaan strategis sistem informasi pelayanan publik adalah Joe Ward and Peppard. Tahapan perencanaan strategis sistem informasi Joe Ward and Peppard ada dua yaitu tahapan masukan dan tahapan keluaran [2]. Tahapan masukan meliputi Analisis Lingkungan Bisnis Internal dan Eksternal, analisis Lingkungan bisnis SI/TI Internal dan Eksternal. Sedangkan tahapan keluarannya yaitu strategi bisnis, dan strategi IT. Untuk menganalisa tahapan masukan dan keluaran tersebut dapat menggunakan beberapa analisis seperti analisis SWOT, Critical Success Factor (CSF), Value Chain, dll.

Sebagai salah satu Institusi Pemerintah yang juga mengemban misi untuk mencapai Industri 4.0 Kejaksaan Tinggi Sumatera Selatan juga turut membangun sistem pelayanan publik, namun secara teknis masih belum berjalan sesuai tujuannya. Hal ini dikarenakan tidak terupdatenya sistem data sehingga masyarakat kurang mengetahui informasi yang ada dalam ruang lingkup hukum ataupun kejaksaan itu sendiri [3]. Untuk mecapai tujuan awal tersebut maka Kejaksaan Tinggi Sumatera Selatan membutuhkan perencanaan strategis untuk mempersiapkan organisasi dalam merencanakan pemakaian teknologi dan sistem informasi untuk organisasinya, serta untuk menyesuaikan gerak langkah organisasi dengan sistem informasi agar sejalan dengan perkembangan organisasi dalam memenuhi kebutuhan sistem informasi organisasi di masa yang akan datang.

\section{METODE PENELITIAN}

Dalam penelitian ini penulis menggunakan metode penelitian kualitatif. Penelitian kualitatif menurut pada umumnya menekankan pada analisis proses dari proses berpikir secara deduktif dan induktif yang berkaitan dengan dinamika hubungan antar penelitian yang diteliti dengan menggunakan logika ilmiah [4]. Penelitian kualitatif dapat dipandang juga sebagai penelitian partisipatif yang desain penelitiannya memiliki sifat fleksibel yang memungkinkan adanya perubahan, guna menyesuaikan dengan rencana yang dibuat sesuai dengan kondisi pada tempat penelitian tersebut.

Secara umum teknik perencanaan strategis sistem informasi pelayanan publik Joe Ward and Peppard terdiri dari tiga tahapan utama yaitu tahap masukan, tahap perumusan dan tahap keluaran yang dijabarkan dalam gambar 1 : 


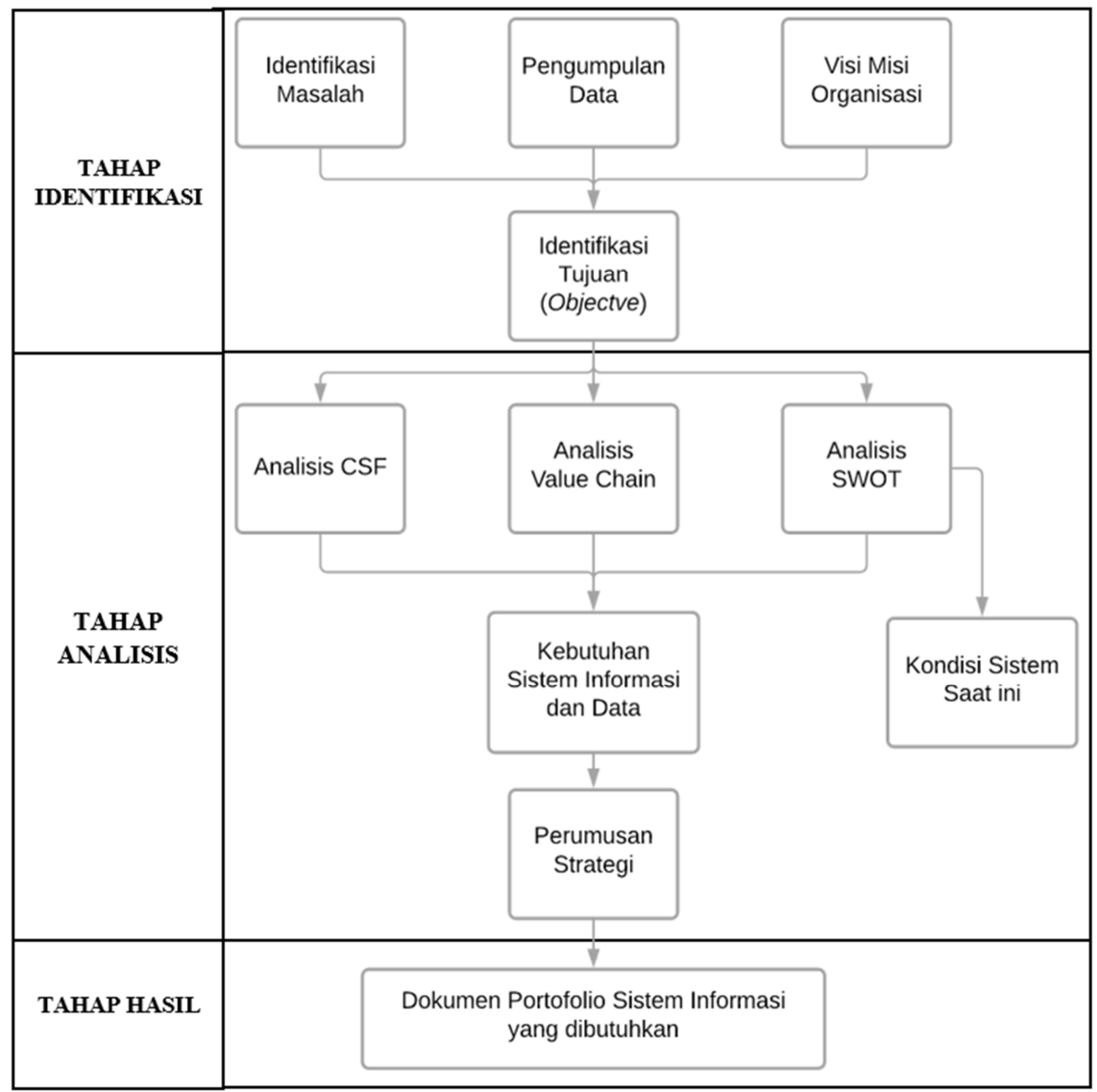

Gambar 1. Alur Metodologi Perencanaan Strategis Joe Ward and Peppard

\section{$2.1 \quad$ Metode Pengumpulan Data}

Pengumpulan data adalah prosedur yang sistematis dan standar untuk memperoleh data yang diperlukan. Berikut ini terdapat beberapa cara yang peneliti lakukan untuk mengumpulkan berbagai data yang diperlukan penelit yang dijabarkan dalam Tabel 1:

Tabel 1. Teknik Pengumpulan Data

\begin{tabular}{|l|l|l|}
\hline No. & Jenis Data & Teknik Pengumpulan data \\
\hline 1. & Premier & $\begin{array}{l}\text { 1. Observasi } \\
\text { 2. Wawancara } \\
\text { 3. Kuesioner }\end{array}$ \\
\hline 2. & Sekunder & 1. Data dari Website resmi Kejaksaan Tinggi Sumatera Selatan \\
\hline
\end{tabular}

\subsection{Metode Analisis Data}

Dalam penelitian ini peneliti melakukan analisis data yang didapatkan pada tahapan sebelumnya dengan menggunakan tiga teknik yang berbeda yaitu Metode analisis SWOT, Metode analisis Critical Success Factor (CSF) dan metode Analisis Value Chain [5]. 


\section{2.1 Metode Analisis SWOT}

Analisis SWOT (Strengths, Weaknesses, Opportunities, Threats) digunakan untuk menilai kekuatan dan kelemahan dari sumber daya yang dimiliki oleh instansi dan kesempatan eksternal serta tantangan yang akan dihadapi [4]. Hasil analisis yang didapat selanjutnya akan dituangkan ke dalam matrik analisis untuk menentukan perencanaan strategi seperti pada matriks dibawah ini.

Tabel 2. Matrik SWOT

\begin{tabular}{|c|c|c|}
\hline SW & STRENGTHS & WEAKNESS \\
\hline OT & $\begin{array}{l}\text { Menentukan faktor-faktor } \\
\text { kekuatan internal }\end{array}$ & $\begin{array}{l}\text { Menentukan faktor-faktor } \\
\text { kelemahan internal }\end{array}$ \\
\hline OPPORTUNITIES & STRATEGI SO & STRATEGI WO \\
\hline $\begin{array}{l}\text { Menentukan faktor-faktor } \\
\text { kekuatan internal }\end{array}$ & $\begin{array}{l}\text { Menggunakan kekuatan } \\
\text { untuk memanfaatkan } \\
\text { peluang }\end{array}$ & $\begin{array}{lrr}\text { Ciptakan } & \text { strategi yang } \\
\text { meminimalkan } & \text { kelemahan } \\
\text { untuk } & \text { memanfaatkan } \\
\text { peluang } & \end{array}$ \\
\hline THREATS & STRATEGI ST & STRATEGI WT \\
\hline $\begin{array}{l}\text { Menentukan faktor-faktor } \\
\text { kekuatan internal }\end{array}$ & $\begin{array}{lr}\text { Ciptakan strategi } & \text { yang } \\
\text { menggunakan } & \text { kekuatan } \\
\text { untuk mengatasi ancaman }\end{array}$ & $\begin{array}{l}\text { Ciptakan strategi yang } \\
\text { meminimalkan kelemahan } \\
\text { dan menghindari ancaman }\end{array}$ \\
\hline
\end{tabular}

\section{2.2 Metode Analisis Critical Success Factor (CSF)}

Pada tahap analisis CSF digunakan untuk sebagai penghubung antara strategi bisnis organisasi dengan strategi sistem informasinya, memfokuskan proses perencanaan strategi SI pada area yang strategis, memprioritaskan usulan sistem informasi dan mengevaluasi strategi SI[6].

\section{2.3 Metode Analisis Value Chain}

Analisis Value chain digunakan untuk mengetahui seluruh aktivitas bisnis baik itu berupa aktivitas utama maupun aktivitas pendukung perusahaan. Aktivitas bisnis utama yang terdapat pada Kejaksaan Tinggi Sumatera Selatan yaitu dalam pelayanan masyarakat, pusat pengaduan, media informasi, zona integritas, konsultasi hukum dan lain sebagainya [2].

\section{HASIL DAN PEMBAHASAN}

\section{1 Metode Analisis SWOT}

Dalam proses analisis data - data yang terkumpul dari Kejati Sumsel, menggunakan analisis SWOT (Strengthness, Weakness, Opportunities, Threatment) didapatkan hasil sebagai berikut:

1. Kekuatan (Strengthness)

Berikut merupakan indikasi-indikasi dalam meningkatkan daya saing serta meningkatkan keberhasilan penerapan SI/TI pada Kejaksaan Tinggi Sumatera Selatan: 
- (S1) Adanya dukungan dari jajaran pimpinan Kejati Sumsel.

- (S2) Tersedianya SDM pada bagian SI/TI yng mumpuni untuk mengelola perangkat lunak dan perangkat keras pada Kejaksaan Tinggi Sumatera Selatan.

- (S3) Adanya sistem pelayanan terpadu dan terintegrasi.

- (S4) Adanya sistem distribusi, disposisi dan manajemen persuratan secara elektronik.

- (S5) Kemampuan menyediakan anggaran, peralatan, SDM, serta infrastruktur untuk menunjang layanan masyarakat.

2. Kelemahan (Weakness)

Berikut merupakan beberapa indikasi yang dianggap sebagai penyebab kelemahan dari perencanaan penerapan SI/TI pada Kejaksaan Tinggi Sumatera Selatan.

- (W1) Tidak ada kajian penelitian tentang pengembangan SI/TI pada Kejaksaan Tinggi Sumatera Selatan.

- (W2) Terbatasnya jumlah SDM dalam menangani perangkat lunak dan perangkat keras yang ada di Kejati Sumatera Selatan, sehingga menyebabkan pengerjaan suatu trouble menjadi menumpuk.

- (W3) Kurangnya pengembangan dan penelitian tentang SI/TI sehingga kebanyakan aplikasi dan sistem informasi dalam status out dated.

- (W4) Lambannya maintenance pada bagian TI yang baru mulai perbaikan ketika ada masalah terhadap Sistem dan Aplikasi.

- (W5) Kurangnya standarisasi terhadap pengadaan infrastruktur sehingga banyak menyebabkan tidak didukungnya perangkat keras pada pelayanan sistem informasi.

- (W6) Rendahnya pengamanan sistem informasi milik Kejati Sumsel.

- (W7) Kurangnya budaya menggunakan teknologi (IT) dalam lingkungan internal Kejati Sumsel.

3. Peluang (Opportunities)

Berikut merupakan indikasi-indikasi yang dapat dianggap sebagai peluang terhadap penyelenggaraan perencanaan SI/TI pada Kejaksaan Tinggi Sumatera Selatan:

- (O1) Banyaknya penelitian dan pengembangan teknologi dari pihak lain yang dapat dijadikan contoh untuk melakukan pengembangan/development.

- (O2) Antusiasme dan dukungan masyarakat untuk mengembangkan layanan berbasis teknologi pada Kejaksaan Tinggi Sumatera Selatan.

- (O3) Tuntutan masyarakat untuk menciptakan pelayanan yang cepat, bermutu dan ramah termasuk pelayanan-pelayanan yang dimiliki oleh pihak Kejaksaan Tinggi Sumatera Selatan yang sesuai dengan kebutuhan masyarakat.

- (O4) Meningkatnya laporan dan pengaduan masyarakat tentang tindak pidana dan perdata.

- (O5) Kerjasama dengan ahli teknologi untuk melakukan System Hardening dan Pentesting Aplikasi.

4. Ancaman (Threatment)

Berikut merupakan indikasi-indikasi yang dapat dianggap sebagai ancaman terhadap penyelenggaraan perencanaan SI/TI pada Kejaksaan Tinggi Sumatera Selatan:

- (T1) Regulasi pemerintah tentang Sistem Manajemen Pengamanan Informasi.

- (T2) Regulasi Standar Operasional Teknologi Informasi yang meningkat.

- (T3) Berubahnya tuntunan layanan dari masyarakat dan pemerintah pusat.

- (T4) Potensi serangan hacker dan cracker terhadap sistem informasi dan aplikasi Kejati Sumsel.

- (T5) Terdapatnya gangguan dari ketersediaan layanan dari pihak ketiga. 
- (T6) Kurangnya pengetahuan masyarakat awam tentang cara penggunaan sistem informasi yang disediakan.

Tabel 3. Matrik Evaluasi Internal dan Eksternal

\begin{tabular}{|c|c|c|c|c|}
\hline Faktor Dimensi Internal & Jumlah & Bobot \% & Rating & Total $B * R$ \\
\hline \multicolumn{5}{|l|}{ Kekuatan (S) } \\
\hline S1 & 50 & $22 \%$ & 5 & 1,1 \\
\hline S2 & 44 & $19,4 \%$ & 4.4 & 0.85 \\
\hline S3 & 43 & $18,9 \%$ & 4.3 & 0.81 \\
\hline S4 & 45 & $19,8 \%$ & 4.5 & 0.89 \\
\hline S5 & 45 & $19,8 \%$ & 4.5 & 0.89 \\
\hline Total & 227 & 1 & \multicolumn{2}{|l|}{4.553} \\
\hline \multicolumn{5}{|l|}{ Kelemahan (W) } \\
\hline W1 & 38 & $14 \%$ & 3.8 & 0.54 \\
\hline W2 & 38 & $14 \%$ & 3.8 & 0.54 \\
\hline W3 & 40 & $15 \%$ & 4 & 0.6 \\
\hline W4 & 38 & $14 \%$ & 3.8 & 0.54 \\
\hline W5 & 39 & $16 \%$ & 3.9 & 0.57 \\
\hline W6 & 35 & $13 \%$ & 3.5 & 0.46 \\
\hline W7 & 37 & $14 \%$ & 3.7 & 0.51 \\
\hline Total & 265 & 1 & \multicolumn{2}{|l|}{3.791} \\
\hline Faktor Dimensi Eksternal & Jumlah & Bobot \% & Rating & Total $B * R$ \\
\hline \multicolumn{5}{|l|}{ Peluang (O) } \\
\hline O1 & 42 & 19 & 4,2 & 0.81 \\
\hline $\mathrm{O} 2$ & 46 & 21 & 4,6 & 0.97 \\
\hline $\mathrm{O} 3$ & 43 & 20 & 4,3 & 0.85 \\
\hline $\mathrm{O} 4$ & 44 & 20 & 4,4 & 0.89 \\
\hline O5 & 43 & 20 & 4,3 & 0.85 \\
\hline Total & 218 & 1 & \multicolumn{2}{|l|}{4.364} \\
\hline \multicolumn{5}{|l|}{ Ancaman (T) } \\
\hline $\mathrm{T} 1$ & 35 & $16,74 \%$ & 3,5 & 0,58 \\
\hline $\mathrm{T} 2$ & 33 & $15,78 \%$ & 3,3 & 0,52 \\
\hline T3 & 34 & $16,26 \%$ & 3,4 & 0,55 \\
\hline $\mathrm{T} 4$ & 36 & $17,22 \%$ & 3,6 & 0,62 \\
\hline T5 & 35 & $16,74 \%$ & 3,5 & 0,58 \\
\hline T6 & 36 & $17,22 \%$ & 3,6 & 0,62 \\
\hline Total & 209 & 1 & \multicolumn{2}{|l|}{3.487} \\
\hline
\end{tabular}

\section{Hasil Penilaian Matrik}

Berdasarkan hasil perhitungan matrik diatas dengan menggunakan perhitungan pada Matrik Faktor Strategi Internal (IFAS) dan Matrik Fktor Startegi Ekternal (EFAS) maka didapatkan hasil penilaian dari masing-masing faktor tersebut, yang kemudian dijadikan kedalam nilai analisa kuadran.

$$
\begin{aligned}
& \text { Nilai Matriks Evaluasi Internal } \\
& =\text { Total Kekuatan }(\mathrm{S}) \\
& =(4.553-3.791) \quad=\mathbf{0 . 7 6 2} \\
& \text { Nilai Matriks Evaluasi Eksternal }=\text { Total Peluang }(\mathrm{O}) \\
& \text { Total Kelemahan (W) } \\
& \text { - } \quad \text { Total Ancaman (T) }
\end{aligned}
$$




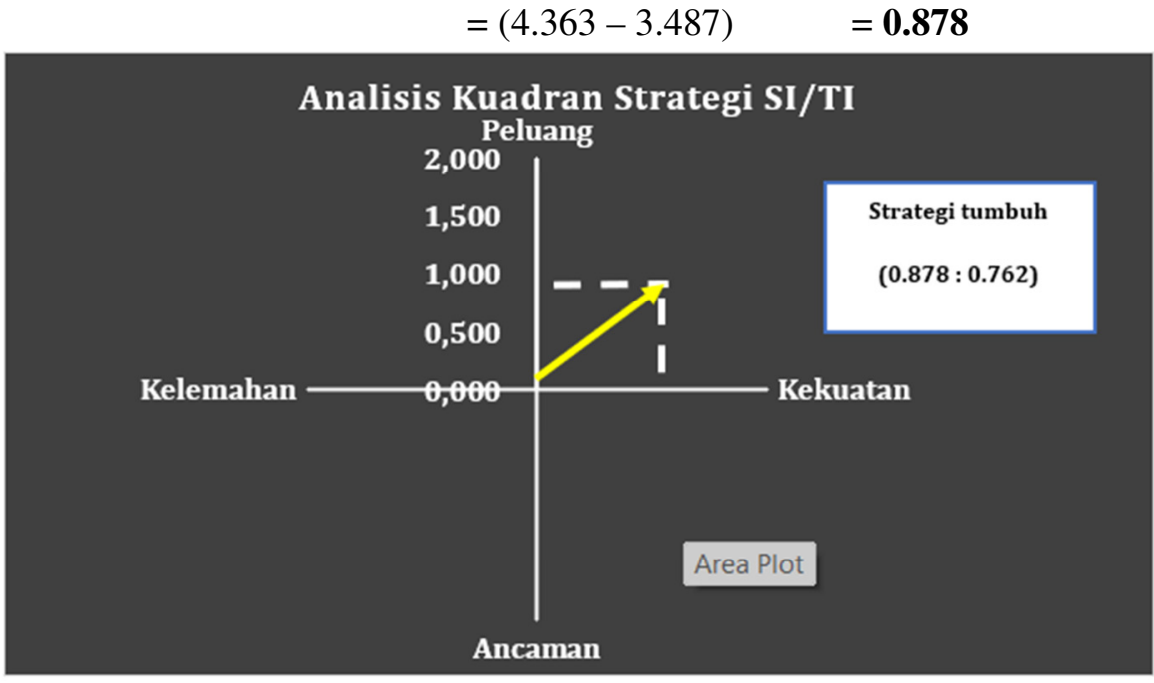

Gambar 2. Analisis Kuadran

Sehingga berdasarkan hasil analisis SWOT didapatkan strategi dalam tabel 3:

Tabel 3. Strategi SWOT

\begin{tabular}{|c|c|}
\hline SO & WO \\
\hline 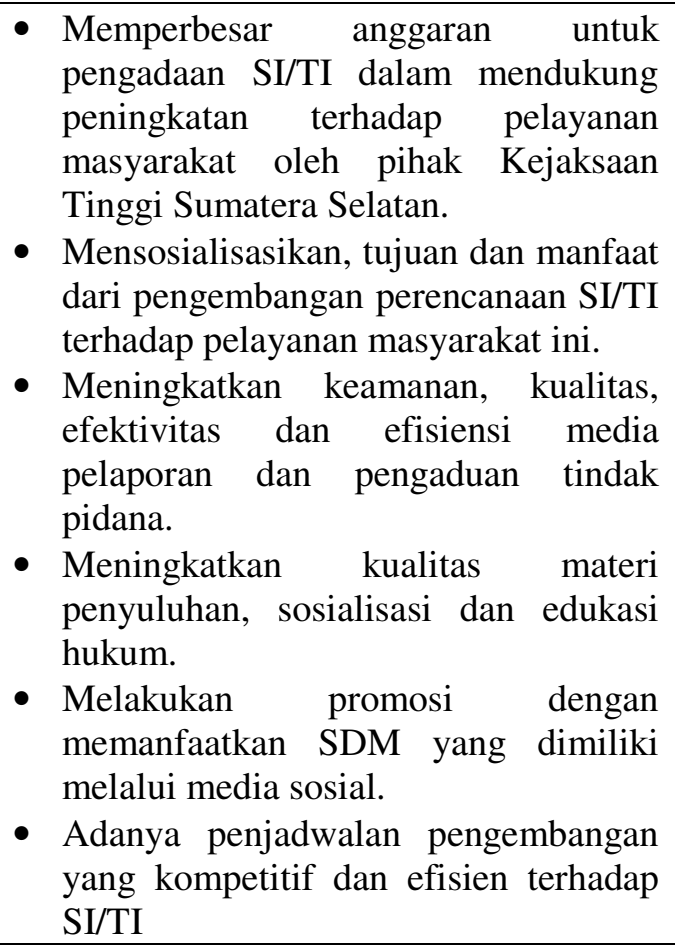 & 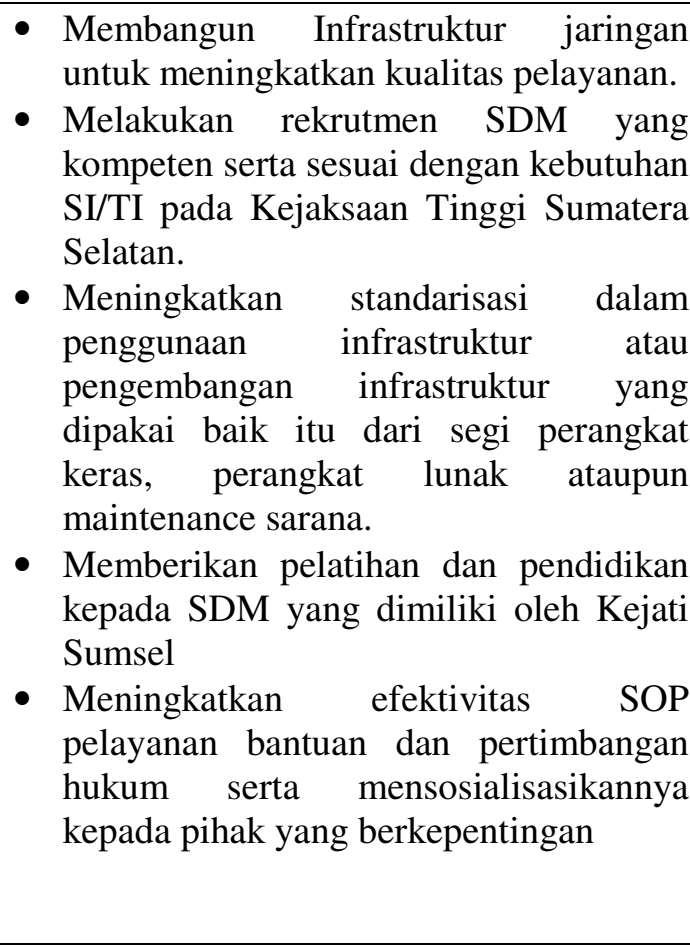 \\
\hline ST & WT \\
\hline $\begin{array}{l}\text { - Meningkatkan standar evaluasi kinerja } \\
\text { jaksa. } \\
\text { - Meningkatkan kualitas sarana dan } \\
\text { prasarana serta infrastruktur yang }\end{array}$ & $\begin{array}{l}\text { - Membangun metode pengumpulan data } \\
\text { dan informasi yang efektif, akurat, dan } \\
\text { efisien. } \\
\text { - Membangun sistem informasi pelayanan }\end{array}$ \\
\hline
\end{tabular}

Khairunnisah, et., al [Perencanaan Strategis TI dalam Pengembangan SI Pelayanan Publik (Studi Kasus: Kejati Sumsel)] 


$\begin{array}{lrr}\text { dimiliki oleh } & \text { Kejaksaan } & \text { Tinggi } \\ \text { Sumatera Selatan. } & \\ \text { Melakukan } & \text { sosialisasi } & \text { terhadap } \\ \text { penggunaan } & \text { layanan } & \text { kepada } \\ \text { masyarakat. } & & \end{array}$

- Meningkatkan keamanan system.

- Meningkatkan kualitas pelayanan bantuan konsultasi hukum kepada masyarakat yang membutuhkan. masyarakat baik itu web ataupun mobile yang dapat diakses oleh masyarakat.

- Mengintegrasikan sistem informasi yang sudah ada.

- Meningkatkan kualitas SDM dengan melakukan pelaksanaan pelatihan manajemen pengamanan sistem informasi.

- Menyesuaikan standar manajemen pengamanan sistem informasi dengan SNI-ISO 27001.

- Adanya cadangan sumber daya jaringan internet ataupun cadangan tenaga listrik agar sistem informasi tetap berjalan optimal tanpa adanya gangguan.

\section{2 Metode Analisis (Critical Success Factor) CSF}

Pada tahap analisis CSF digunakan untuk sebagai penghubung antara strategi bisnis organisasi dengan strategi sistem informasinya, memfokuskan proses perencanaan strategi SI pada area yang strategis, memprioritaskan usulan sistem informasi dan mengevaluasi strategi SI[6].

Tabel 4. Hasil Analisis CSF pada Kejaksaan Tinggi Sumatera Selatan

\begin{tabular}{|c|c|c|}
\hline Tujuan Utama & CSF (Critical Success Factor) & Unit \\
\hline $\begin{array}{lr}\text { Meningkatkan } & \text { peran } \\
\text { kejaksaan } & \text { Tinggi } \\
\text { Sumatera } & \text { Selatan } \\
\text { dalam } & \text { program } \\
\text { pencegahan } & \text { tindak } \\
\text { pidana } & \end{array}$ & 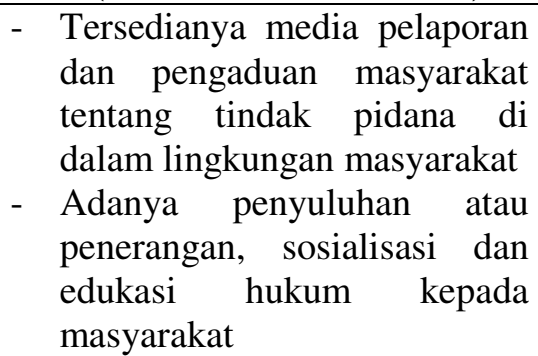 & $\begin{array}{ll}\text { - } & \text { Asisten Bidang Intelijen } \\
\text { - } & \text { Koordinator }\end{array}$ \\
\hline $\begin{array}{l}\text { Meningkatkan } \\
\text { profesionalisme jaksa } \\
\text { dalam penanganan } \\
\text { perkara tindak pidana }\end{array}$ & 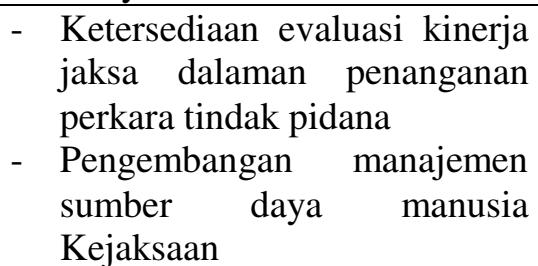 & $\begin{array}{ll}\text { - } & \text { Asisten Bidang Pidana Umum } \\
\text { - } & \text { Asisten Bidang Pidana } \\
& \text { Khusus } \\
\text { - } & \text { Asisten Bidang Pengawasan } \\
\text { - } & \text { Asisten Bidang Pembinaan } \\
\text { - } & \text { Koordinator }\end{array}$ \\
\hline $\begin{array}{l}\text { Meningkatkan peran } \\
\text { jaksa pengacara negara } \\
\text { dalam penyelesaian } \\
\text { masalah perdata dan } \\
\text { tata usaha negara }\end{array}$ & 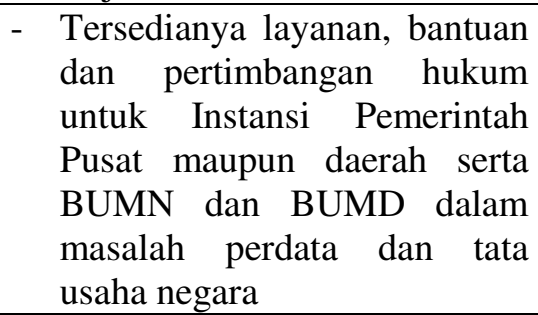 & $\begin{array}{l}\text { - Asisten Bidang Perdata dan } \\
\text { Tata Usaha Negara } \\
\text { - Koordinator }\end{array}$ \\
\hline $\begin{array}{lr}\text { Mewujudkan } & \text { upaya } \\
\text { penegakan } & \text { hukum }\end{array}$ & $\begin{array}{llr} & \text { Transparansi } & \text { informasi } \\
\text { penegakan } & \text { hukum atau }\end{array}$ & $\begin{array}{ll}\text { - } & \text { Seluruh elemen kejaksaan } \\
& \text { Tinggi Sumatera Selatan }\end{array}$ \\
\hline
\end{tabular}




\begin{tabular}{|c|c|c|}
\hline $\begin{array}{l}\text { memenuhi rasa } \\
\text { keadilan masyarakat }\end{array}$ & $\begin{array}{l}\text { tindakan hukum } \\
\text { - Tersedianya informasi tentang } \\
\text { tindak pidana yang ada di } \\
\text { Sumatera Selatan } \\
\text { - Tersedianya bantuan } \\
\text { konsultasi hukum secara adil } \\
\text { untuk seluruh masyarakat } \\
\text { yang membutuhkan }\end{array}$ & \\
\hline $\begin{array}{l}\text { Mempercepat } \\
\text { pelaksanaan reformasi } \\
\text { birokrasi dan tata } \\
\text { kelola } \quad \text { Kejaksaan } \\
\text { Republik Indonesia } \\
\text { yang bersih dan bebas } \\
\begin{array}{l}\text { korupsi, kolusi dan } \\
\text { nepotisme }\end{array}\end{array}$ & $\begin{array}{ll}\text { - } & \begin{array}{l}\text { Tersedianya layanan } \\
\text { informasi bistem }\end{array} \\
\text { berkualitas } & \\
\text { - } & \text { Tersedianya sistem informasi } \\
& \text { tata kelola organisasi } \\
\text { - } & \text { Adanya tahap birokrasi yang } \\
& \text { efektif dan efisien }\end{array}$ & $\begin{array}{ll}\text { - } & \text { Asisten Bidang Pembinaan } \\
\text { - } & \text { Kabag TU }\end{array}$ \\
\hline
\end{tabular}

\section{3 Metode Analisis Value Chain}

Analisis Value chain digunakan untuk mengetahui seluruh aktivitas bisnis baik itu berupa aktivitas utama maupun aktivitas pendukung perusahaan $[3,6]$. Aktivitas bisnis utama yang terdapat pada Kejaksaan Tinggi Sumatera Selatan yaitu dalam pelayanan masyarakat, pusat pengaduan, media informasi, zona integritas, konsultasi hukum dan lain sebagainya. Selanjutnya, untuk aktivitas bisnis penunjang meliputi teknologi dan sistem. Value chain yang terdapat pada Kejaksaan Tinggi Sumatera Selatan dapat dilihat pada gambar 3:

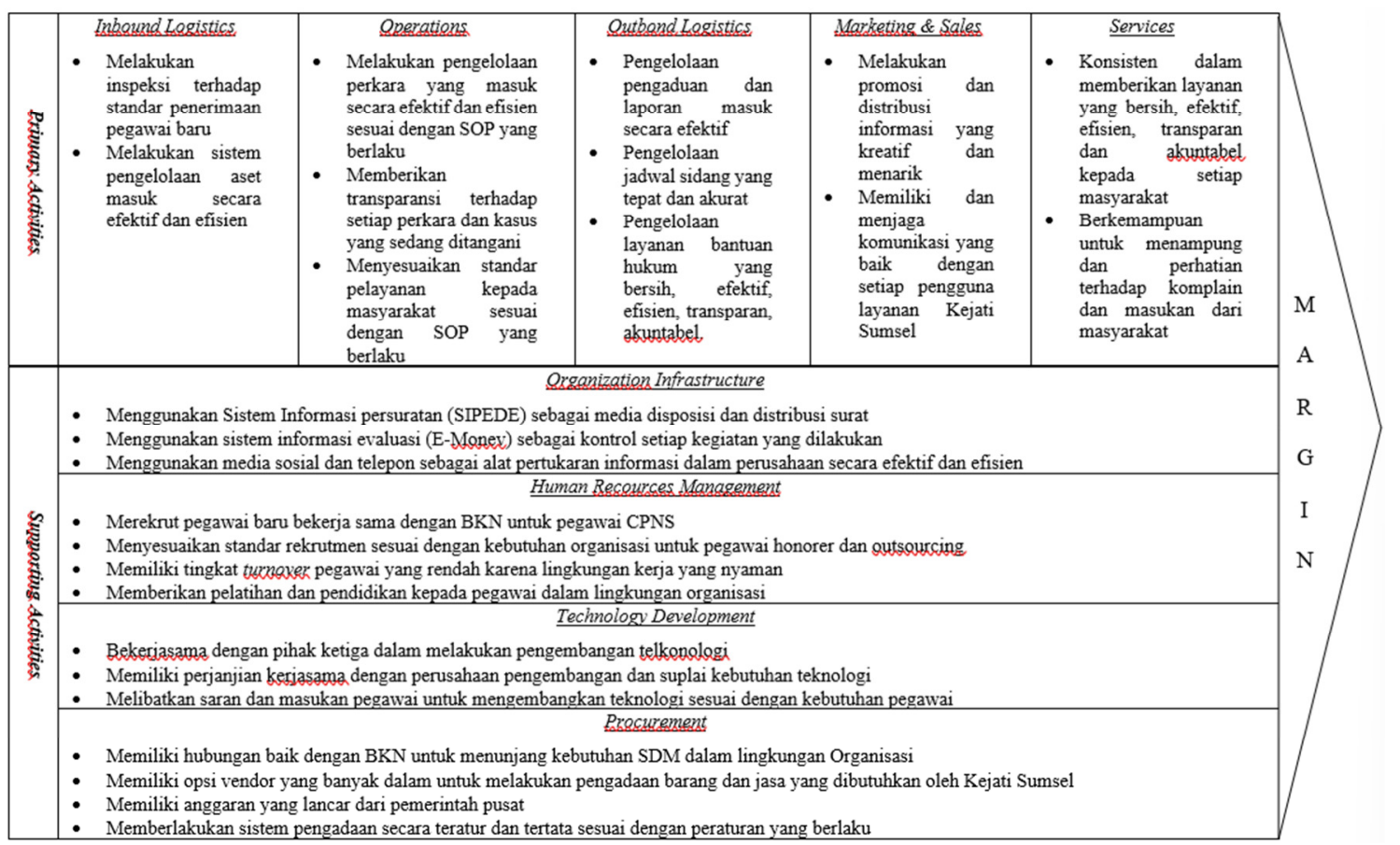

Gambar 3. Strategis Analisis Value Chain 
Dengan pemetaan sistem informasi yang dimiliki oleh Kejati Sumsel seperti dalam gambar 4:

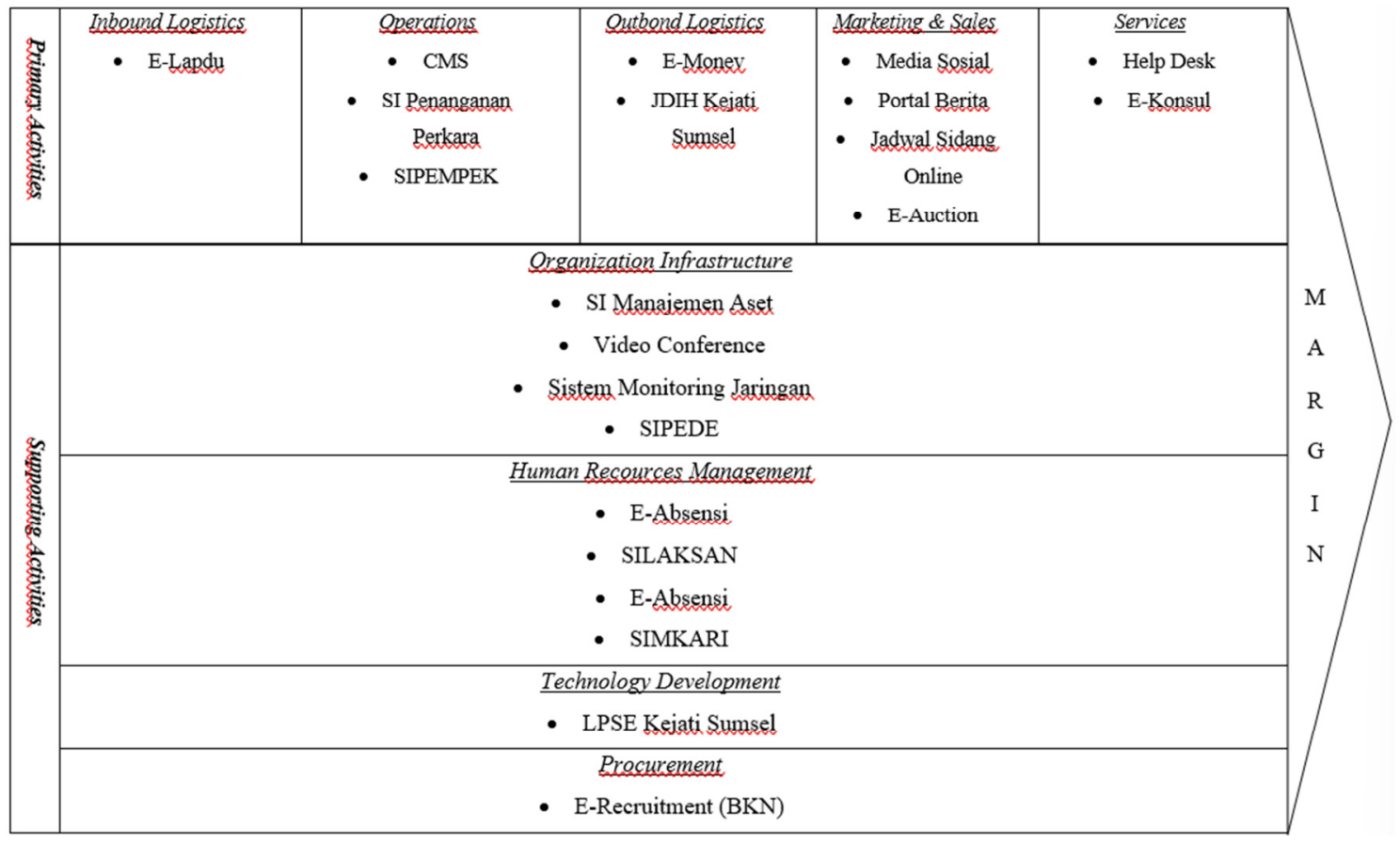

Gambar 4. Pemetaan SI/TI Kejati Sumsel dalam analisis Value Chain

\section{4 Rumusan Strategi SI/TI}

Tabel 5. Rancangan Kebutuhan Informasi dan Data

\begin{tabular}{|c|c|c|}
\hline CSF & Kebutuhan Informasi & Solusi SI/TI \\
\hline $\begin{array}{l}\text { Tersedianya media } \\
\text { pelaporan dan } \\
\text { pengaduan masyarakat } \\
\text { tentang tindak pidana } \\
\text { di dalam lingkungan } \\
\text { masyarakat }\end{array}$ & $\begin{array}{l}\text { - Data inventaris media pengaduan } \\
\text { tindak pidana } \\
\text { - Data arsip perkara tindak pidana } \\
\text { - Data monitoring evaluasi media } \\
\text { pelaporan dan pengaduan }\end{array}$ & $\begin{array}{ll}\text { - } & \text { Case Management } \\
& \text { System (CMS) } \\
\text { - } & \text { SI Manajemen Aset } \\
\text { - SI Penanganan Perkara } \\
\text { - E-Lapdu } \\
\text { - E-Monev }\end{array}$ \\
\hline $\begin{array}{lr}\text { Adanya } & \text { penyuluhan } \\
\text { atau } & \text { penerangan, } \\
\text { sosialisasi } & \text { dan edukasi } \\
\text { hukum } & \text { kepada } \\
\text { masyarakat } & \end{array}$ & $\begin{array}{l}\text { - Data audiens/peserta penyuluhan, } \\
\text { sosialisasi dan edukasi hukum } \\
\text { - Data perkembangan hukum } \\
\text { tindak pidana di Indonesia }\end{array}$ & $\begin{array}{l}\text { - E-Absensi } \\
\text { - Video Conference } \\
\text { - Media Sosial } \\
\text { - Portal Berita } \\
\text { - E-Konsul }\end{array}$ \\
\hline $\begin{array}{lr}\text { Ketersediaan } & \text { evaluasi } \\
\text { kinerja jaksa } & \text { dalam } \\
\text { penanganan } & \text { perkara } \\
\text { tindak pidana } & \end{array}$ & $\begin{array}{l}\text { - Data sasaran kinerja Jaksa Kejati } \\
\text { Sumsel } \\
\text { - Data capaian kinerja Jaksa Kejati } \\
\text { Sumsel }\end{array}$ & $\begin{array}{llr}\text { - } & \text { Sistem } & \text { Informasi } \\
& \text { Manajemen } & \text { Kejaksaan } \\
& \text { RI (SIMKARI) } \\
\text { - } & \text { Sistem } & \text { Informasi } \\
& \text { Laporan } & \text { Sasaran } \\
\text { Kinerja } & \text { Pegawai } \\
& \text { Kejaksaan } & \\
& \text { (SILAKSAN) } & \\
\end{array}$ \\
\hline
\end{tabular}

Khairunnisah, et., al [Perencanaan Strategis TI dalam Pengembangan SI Pelayanan Publik (Studi Kasus: Kejati Sumsel)] 


\begin{tabular}{|c|c|c|}
\hline \begin{tabular}{lr}
\multicolumn{2}{l}{ Pengembangan } \\
manajemen sumber \\
daya & manusia \\
Kejaksaan &
\end{tabular} & $\begin{array}{l}\text { - Data kompetensi dan sertifikasi } \\
\text { jaksa Kejati Sumsel } \\
\text { - Data standar pendidikan dan } \\
\text { kompetensi jaksa Republik } \\
\text { Indonesia }\end{array}$ & $\begin{array}{ll}- & \text { SIMKARI } \\
- & \text { E-Kepegawaian } \\
& (\text { EDOSIR) }\end{array}$ \\
\hline $\begin{array}{lr}\text { Tersedianya } & \text { layanan, } \\
\text { bantuan } & \text { dan } \\
\text { pertimbangan } & \text { hukum } \\
\text { untuk } & \text { Instansi } \\
\text { Pemerintah } & \text { Pusat } \\
\text { maupun daerah serta } \\
\text { BUMN dan BUMD } \\
\text { dalam masalah perdata } \\
\text { dan tata usaha negara }\end{array}$ & $\begin{array}{l}\text { - Data perkara perdata dan tata } \\
\text { usaha negara } \\
\text { - Data Personil jaksa pengacara } \\
\text { negara } \\
\text { - Data standar kompetensi jaksa } \\
\text { pengacara negara }\end{array}$ & $\begin{array}{ll}\text { - } & \text { E-Konsul } \\
\text { - } & \text { CMS } \\
\text { - } & \text { EDOSIR }\end{array}$ \\
\hline $\begin{array}{l}\text { Transparansi informasi } \\
\text { penegakan hukum atau } \\
\text { tindakan hukum }\end{array}$ & $\begin{array}{l}\text { - Data progres perkara yang sedang } \\
\text { ditangani oleh Kejaksaan Tinggi } \\
\text { Sumatera Selatan } \\
\text { - Data Perkara yang sudah selesai }\end{array}$ & $\begin{array}{ll}\text { - } & \text { CMS } \\
\text { - Sistem Informasi } \\
& \text { Pengendalian Perkara } \\
& \text { Pidana (SIPEMPEK) } \\
\text { - Jadwal Sidang Online } \\
\text { - Portal Berita } \\
\end{array}$ \\
\hline $\begin{array}{l}\text { Tersedianya informasi } \\
\text { tentang tindak pidana } \\
\text { yang ada di Sumatera } \\
\text { Selatan }\end{array}$ & $\begin{array}{l}\text { - Data Perkara } \\
\text { - Data Barang Bukti } \\
\text { - Data Putusan Pengadilan } \\
\text { - Data Intelijen }\end{array}$ & 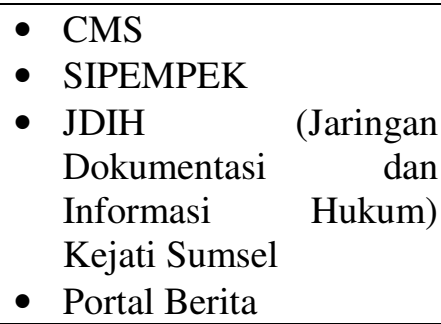 \\
\hline $\begin{array}{lr}\text { Tersedianya } & \text { bantuan } \\
\text { konsultasi hukum } & \text { hirak adil untuk } \\
\text { secara masyarakat } \\
\text { seluruh mankan } \\
\text { yang membutuhkan }\end{array}$ & $\begin{array}{l}\text { - Data tindak lanjut pengaduan dan } \\
\text { pelaporan dari masyarakat }\end{array}$ & $\begin{array}{l}\text { - E-Konsul } \\
\text { - CMS }\end{array}$ \\
\hline $\begin{array}{l}\text { Tersedianya layanan } \\
\text { sistem informasi } \\
\text { birokrasi yang efektif } \\
\text { dan efisien }\end{array}$ & $\begin{array}{l}\text { - Data kendala dalam pelaksanaan } \\
\text { birokrasi lingkungan internal dan } \\
\text { eksternal Kejaksaan Tinggi } \\
\text { Sumatera Selatan } \\
\text { - Data kecepatan dan ketepatan } \\
\text { penyelesaian persuratan dan } \\
\text { administrasi Kejati Sumsel } \\
\end{array}$ & $\begin{array}{ll}\text { - } & \text { Sistem Informasi } \\
& \text { Persuratan Disposisi } \\
& \text { Elektronik (SIPEDE) } \\
\text { - } & \text { E-Komplain }\end{array}$ \\
\hline $\begin{array}{ll}\text { Tersedianya } & \text { sistem } \\
\text { informasi tata } & \text { kelola } \\
\text { organisasi } & \end{array}$ & $\begin{array}{l}\text { - Data pengadaan Kejati Sumsel } \\
\text { - Data pengelolaan Infrastruktur } \\
\text { Kejati Sumsel } \\
\text { - Data inventaris sarana dan } \\
\text { Prasarana Kejati Sumsel }\end{array}$ & $\begin{array}{l}\text { - LPSE Kejati Sumsel } \\
\text { - SI Manajemen Aset } \\
\text { - E-Auction } \\
\text { - Sistem Monitoring } \\
\text { - Jaringan } \\
\text { - Help Desk Application } \\
\end{array}$ \\
\hline
\end{tabular}


Berdasarkan hasil analisis SWOT, CSF dan Valuchain di atas rencana strategis yang dirancang untuk Kejati Sumsel adalah sebagai berikut:

1. Bekerja sama dengan BKN dalam melakukan penerimaan pegawai baru

2. Merekrut ahli sebagai PPPK

3. (Rekomendasi SDM seperti praktisi SI/TI, Dosen dan tenaga ahli lainnya)

4. Menyesuaikan standar penerimaan pegawai baru dengan kebutuhan pegawai dalam bidang SI/TI

5. Melakukan pelatihan SDM untuk meningkatkan kompetensi dan kemampuan di bidang $\mathrm{SI} / \mathrm{TI}$

6. (Jenis pelatihan yang direkomendasikan: ISO 27001, CHFI, CEH, dan lain-lain)

7. Melakukan latihan gabungan tahunan dengan seluruh Kejaksaan Negeri yang ada di Sumatera Selatan

8. Melakukan studi banding / benchmark terkait SI/TI kepada perusahaan dengan SI/TI yang lebih baik seperti BSSN, KOMINFO, dan lain-lain

9. Membuat unit kerja untuk melakukan penelitian dan pengembangan SI/TI Kejati

10. Membuat tim monitoring SI/TI Kejati

11. Membuat tim incident response

12. Menyusun penganggaran sesuai dengan DIPA Kejati Sumsel secara seimbang antara kemampuan dan kebutuhan

13.

14. Pengadaan peralatan yang dibutuhkan seperti infrastruktur jaringan yang terintegrasi, perangkat penunjang pekerjaan seperti server, komputer, koneksi internet, ATK, dan lainlain.

15. Melakukan penyusunan daftar peralatan yang dibutuhkan baik melalui rapat maupun penelitian dan observasi

16. Pembuatan kebijakan berupa Keputusan Kepala Kejaksaan Tinggi Sumatera Selatan dan Peraturan Kepala Kejaksaan Tinggi Sumatera Selatan sebagai dasar penggunaan SI/TI dilingkungan Kejati Sumsel

17. Pembuatan SOP penggunaan alat/aplikasi

18. Pembuatan SOP penanganan insiden SI/TI

19. Melakukan integrasi SI/TI Kejati Sumsel dengan SI/TI Kejaksaan Agung

20. Melakukan integrasi SI/TI kepada seluruh Kejari di Sumsel

21. Sharing SI/TI kepada seluruh Kejaksaan Negeri yang berada di Sumatera Selatan

22. Mengelola media-media promosi kegiatan dan layanan seperti berita online, sosial media dan lain-lain

23. Membuat contact center yang mudah dijangkau oleh masyarakat seperti hotline telepon, Whatsapp, PTSP.

24. Membuat sistem pelayanan online sehingga pelayanan dapat dilakukan secara lebih cepat dan efektif

\subsubsection{Portofolio Aplikasi Kejati Sumatera Selatan}

\begin{tabular}{|l|l|}
\hline Strategic & High Potential \\
\hline - CMS (Upgrade) & $\bullet$ SI Manajemen Aset (Add) \\
- SI Penanganan Perkara (Add) & - E-Monev (Upgrade) \\
- E-Lapdu (Upgrade) & - Media Sosial (Upgrade) \\
- SIPEMPEK (Upgrade) & - Portal Berita (Upgrade) \\
& - E-Konsul (Upgrade) \\
\hline
\end{tabular}

Khairunnisah, et., al [Perencanaan Strategis TI dalam Pengembangan SI Pelayanan Publik (Studi Kasus: Kejati Sumsel)] 


\begin{tabular}{|l|l|}
\hline & $\bullet$ JDIH Kejati Sumsel (Add) \\
& $\bullet$ E-Auction (Add) \\
\hline - SIMKARI (Upgrade) & $\bullet$ E-Absensi (Add) \\
- SILAKSAN (Upgrade) & $\bullet$ Video Conference (Upgrade) \\
- SIPEDE (Upgrade) & • Sistem Monitoring Jaringan (Add) \\
- LPSE Kejati Sumsel (Add) & $\bullet$ Help Desk (Add) \\
\hline - Jadwal Sidang Online (Add) & \\
\hline Key Operational & Support \\
\hline
\end{tabular}

\section{KESIMPULAN}

Pada era revolusi Industri 4.0 penyebaran dan akses informasi secara cepat, tepat dan akurat merupakan hal yang sangat mutlak diperlukan. Setiap elemen yang ingin mencapai revolusi industri 4.0 diharuskan untuk beradaptasi dan berkembang mengikuti perubahan yang semakin pesat. Tanpa terkecuali Kejaksaan Tinggi Sumatera Selatan (Kejati Sumsel) yang menjadi fokus penelitian ini.

Perencanaan strategi SI bertujuan untuk memperoleh solusi sistem informasi beserta teknologi didalamnya. Solusi SI yang diusulkan mendukung visi, misi, dan proses bisnis di Kejaksaan Tinggi Sumatera Selatan. Solusi SI ini diidentifikasi berdasarkan analisis SWOT, CSF dan Value chain. Berdasarkan identifikasi analisis SWOT melalui analisis kuadran dari sisi IT dan Bisnis baik itu Internal dan Eksternal menunjukkan adanya strategi tumbuh yang artinya disetujui untuk dilakukan pengembangan terhadap SI/IT pada Kejati Sumsel dengan fokus memanfaatkan kekuatan dan peluang yang ada. Hasil dari pengumpulan data dan analisis yang telah dilaksanakan yaitu ada beberapa hal yang perlu diperbaiki seperti keamanan sistem informasi dan aplikasi, tambahan aplikasi SI (berkaitan dengan aktivitas utama Kejati Sumsel) dan fleksibilitas proses pengaksesan informasi yang dibutuhkan oleh masyarakat. Analisa yang telah digunakan untuk mendapatkan informasi yang dibutuhkan yaitu analisa SWOT, value chain dan critical success factor, serta penggunaan analisis PEST (Political, Economic, Social, Tehnology) untuk mendeskripsikan kondisi yang ada dari Kejaksaan Tinggi Sumatera Selatan. Sehingga hasil analisa yang didapatkan yaitu Kejati Sumsel telah memiliki sistem informasi yang dapat menunjang kegiatan utama yaitu SIPEDE, SIPEMPEK, SILAKSAN, E-Monev, SIMKARI, EDOSIR, E-LAPDU, Portal Berita dan Media Sosial. Berdasarkan informasi tersebut portofolio aplikasi yang dibutuhkan oleh Kejati Sumsel yaitu penambahan 10 Aplikasi dan sistem informasi baru dan perbaikan 11 aplikasi yang sudah ada dengan sebaran sebagai berikut : perbaikan 3 aplikasi dan penambahan 1 aplikasi pada level strategic, perbaikan 4 aplikasi dan penambahan 1 aplikasi pada level high potential, perbaikan 3 aplikasi dan penambahan 2 aplikasi pada level Key Operational, dan perbaikan 1 aplikasi dan penambahan 5 aplikasi pada level support.

\section{SARAN}

Setiap perencanaan strategis suatu instansi akan mempertimbangkan aspek-aspek manajemen risiko, maka saran penulis agar dilakukan analisis dan manajemen resiko terhadap sistem informasi yang baru dikembangkan. Serta menjadikan penelitian sebagai bahan pertimbangan dan petunjuk atau guide bagi instansi dalam pembuatan rencana strategis pengembangan sistem informasi organisasi. 


\section{UCAPAN TERIMA KASIH}

Penulis mengucapkan terima kasih kepada pihak - pihak yang telah terlibat dan mendukung penelitian ini.

\section{DAFTAR PUSTAKA}

[1] Kementerian Pendayagunaan Aparatur Negara, 2003. "Keputusan Menteri Pendayagunaan Aparatur Negara No.63 tahun 2003.” Republik Indonesia,

[2] N. Sujana, 2017, "Perencanaan Strategis Sistem Informasi Dengan Pendekatan Ward and Peppard," TEMATIK, Vol. 4, No. 1, pp. 68-85, Jun. 2017, doi: 10.38204/tematik.v4i1.173.

[3] Kejaksaan Agung Republik Indonesia, “ Pengertian Kejaksaan.” https://www.kejaksaan.go.id/profil_kejaksaan.php?id=1 (accessed Jun. 19, 2021).

[4] E. S. Negara, 2016, "Analisis dan Perancangan Arsitektur Teknologi Informasi Berbasis Cloud Computing Untuk Institusi Perguruan Tinggi di Sumatera Selatan,” JURNAL TEKNOLOGI Technoscientia, Vol. 8, No. 2, pp. 141-146, Feb. 2016.

[5] W. Syafitri, 2016, "Perencanaan Strategi Sistem Informasi/Teknologi Informasi Universitas Lancang Kuning Menggunakan Metode Ward and Peppard," Digital Zone: Jurnal Teknologi Informasi dan Komunikasi, Vol. 7, No. 1, pp. 33-43, Feb. 2016.

[6] Y. Utami, A. Nugroho, and A. F. Wijaya, 2018, "Perencanaan Strategis Sistem Informasi dan Teknologi Informasi pada Dinas Perindustrian dan Tenaga Kerja Kota Salatiga," Jurnal Teknologi Informasi dan Ilmu Komputer, Vol. 5, No. 3, p. 253, Aug. 2018, doi: 10.25126/jtiik.201853655.

[7] J. Ward, P. M. Griffiths, P. Whitmore, and J. Peppard, 2002. Strategic Planning for Information Systems, 3rd ed. Chichester: John Wiley and Sons Ltd, 